\title{
INVESTIGATION OF DYNAMIC CHARACTERISTICS OF MULTI-BLADED S-SHAPED VANE TYPE ROTOR
}

\author{
Z. Afroz*, M.Q. Islam and M. Ali \\ Department of Mechanical Engineering, \\ Bangladesh University of Engineering and Technology (BUET), Dhaka-1000, Bangladesh. \\ *Corresponding e-mail: zakia_afroz@yahoo.com
}

\begin{abstract}
In the present research work the dynamic conditions of Multi S-shaped bladed rotor at different Reynolds number have been identified. The investigation on wind loading and aerodynamic effects on the four, five and six bladed $S$-shaped vertical axis vane type rotor has been conducted with the help of an open circuit subsonic wind tunnel. For different bladed rotor the flow velocities were varied from $5 \mathrm{~m} / \mathrm{s}$ to $9 \mathrm{~m} / \mathrm{s}$ covering the Reynolds numbers up to $1.35 \times 10^{5}$. It was experiential that by increasing the number of blades of rotor to the optimum limit considering all significant factors and at the same time by increasing its Reynolds number, the power output can be increased to its maximum level Finally, the nature of predicted dynamic characteristics has been examined by comparing with the existing research works.
\end{abstract}

Keywords: Rotor, Dynamic characteristics, Multi-blade, Reynolds number.

\section{INTRODUCTION}

The utilization of wind energy is not a new technology but draws on the rediscovery of a long tradition of wind power technology. However, expected developments have not been achieved in wind driven machines to cope with the characteristics of wind turbines. Conventional machines ${ }^{1}$ are being used now a day even though they are not always suitable from the operational point of view. Arising from the increasing practical importance of wind turbine aerodynamics, there have been, over the past few decades, enormous increases in research works concerning laboratory simulations, full-scale measurements and more recently, numerical calculations and theoretical predictions of flows over a wide variety of vane type wind turbine. Bowden and McAleese ${ }^{2}$ made some measurements on the Queensland optimum Sshaped rotor to examine the properties of isolated and coupled S-shaped rotor. Huda et al. ${ }^{3}$ analyzed the performance of S-shaped rotor by placing a flat plate in front of the returning blade. Islam et al. ${ }^{5}$ investigated the aerodynamic forces acting on a stationary S-shaped rotor and made an attempt to predict the dynamic performance from these forces.

This paper reports on the investigation on wind loading and aerodynamic effects on the four, five and six bladed S-shaped vertical axis vane type rotor conducted with the help of a subsonic wind tunnel together with the experimental set-up of the vane type rotor and a spring balance. This Vane type rotor of Sshaped cross section is predominantly drag based, but also uses a certain amount of aerodynamic lift. Drag based vertical axis wind turbines have relatively higher starting torque and less rotational speed than their lift based counterparts. Furthermore, their power output to weight ratio is also less. Because of the low speed, these are generally considered unsuitable for producing electricity, although it is possible by selecting proper gear trains. Drag based windmills are useful for other applications such as grinding grain, pumping water and a small output of electricity. A major advantage of drag based vertical axis wind turbines lies in their self-starting capacity, unlike the Darrieus lift-based vertical axis wind turbines.

\section{SET-UP OF THE EXPERIMENT}

The experiment was carried out in the open circuit subsonic wind tunnel with an outlet test section of (490 $\mathrm{mm} \times 490 \mathrm{~mm}$ ) cross-section and the rotor was positioned at the exit section of the wind tunnel. The rotors were made of PVC material. Both the top and bottom ends of the rotor were fitted with end caps. The whole rotor was fixed on an iron frame by using a shaft that was inserted into it and two ball bearings. A pulley was attached at one end of shaft. A strip whose one side was tied to a spring balance and other side to a load carrying plate was prepared for passing over that pulley. A radium sticker was attached to that side of shaft. The spring balance was attached to the iron frame. The whole experimental set-up is shown in Fig. 1.

The cross-sectional and three dimensional views of four, five and six bladed S-shaped vane type rotors are shown in Figure 2.

\section{RESULTS AND DISCUSSIONS}

The results for four, five and six bladed S-shaped Vane Type Rotor in terms of power co-efficient versus tip speed ratio for increasing Reynolds number are shown in Figures 3, 4 and 5 respectively.

From these graphs (Figures 3-5) it is apparent that with the increase of Reynolds number the maximum 
value of power coefficient also increases and it is shifted towards the higher values of tip speed ratios. In Figures 6 to 10 comparisons have been made among the curves of power co-efficient versus tip speed ratio of multi-bladed rotor at different Reynolds number.
From these graphs (Figures 6-10) it is evident that with the increase in number of blades the maximum value of power coefficient also increases and it is shifted towards the lower values of tip speed ratio.

1. CONVERGING MOUTH ENTRY

2. PERSPEX SECTION

3. RECTANGULAR DIVERGING SECTION

4. FAN SECTION

5. BUTTERFLY SECTION

6. SILENCER WITH HONEYCOMB SECTION

7. DIVERGING SECTION

8. CONVERGING SECTION

9. RECTANGULAR SECTION

10. FLOW STRAIGHTNER SECTION

11. RECTANGULAR EXIT SECTION

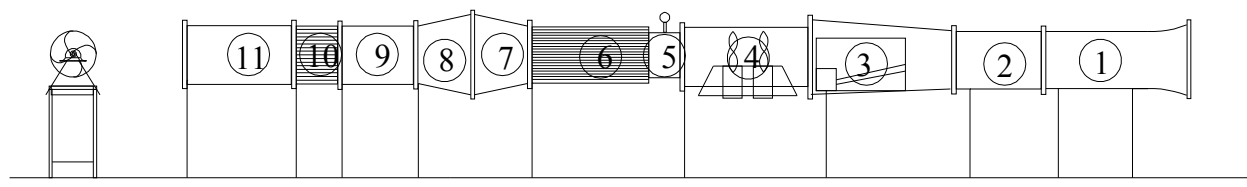

Figure 1. Schematic diagram of wind tunnel

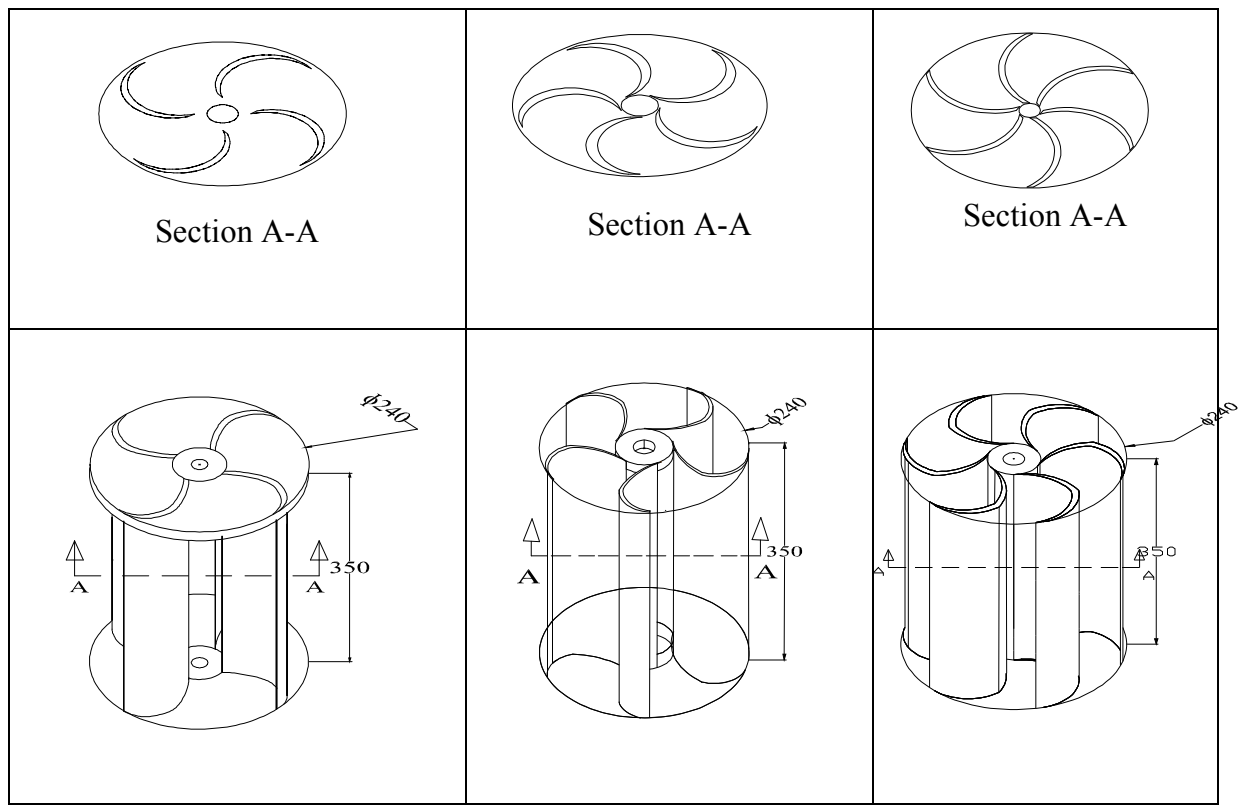

All dimensions are in $\mathrm{mm}$

Figure 2. Cross-sectional and three dimensional views of four, five and six bladed rotor.

Journal of Mechanical Engineering, Vol. ME 44, No. 1, June 2014

Transaction of the Mechanical Engineering Division, The Institution of Engineers, Bangladesh 


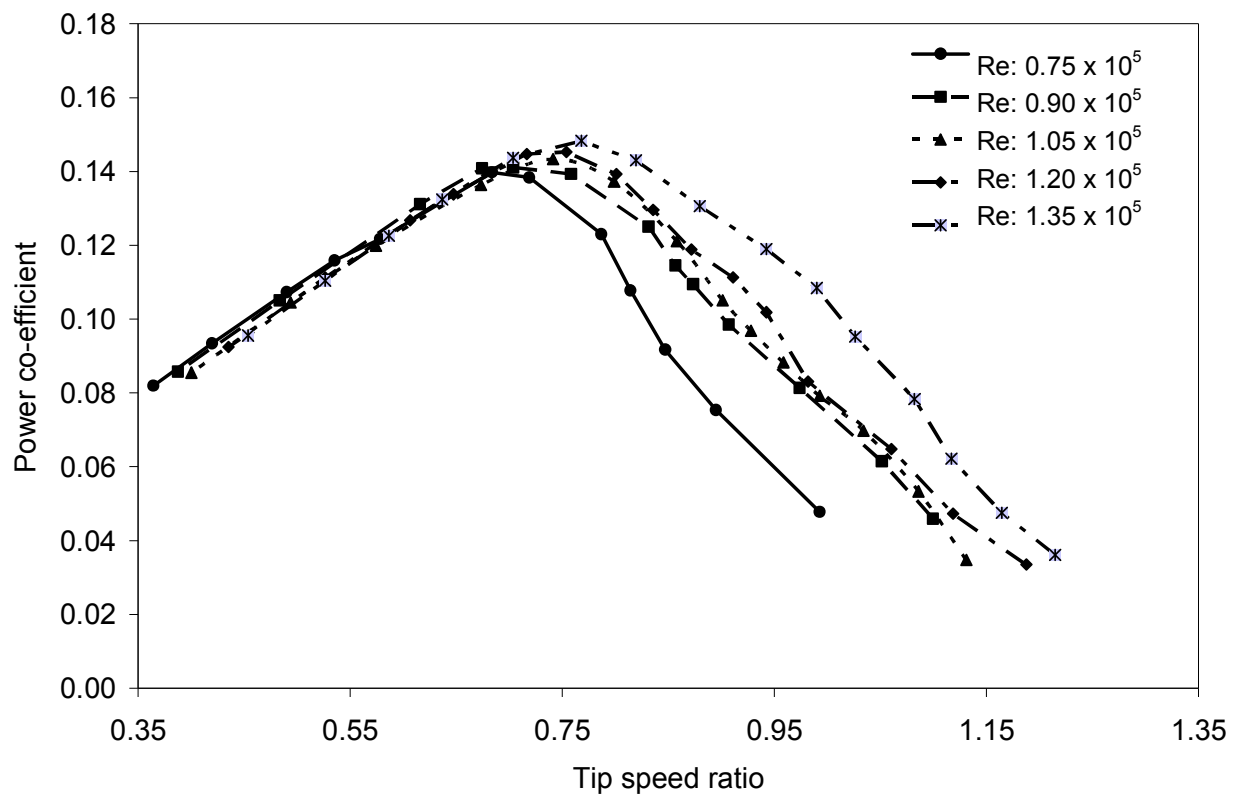

Figure 3. Comparisons of power coefficient vs. tip speed ratio for Four Bladed S-shaped Rotor at different Reynolds number.

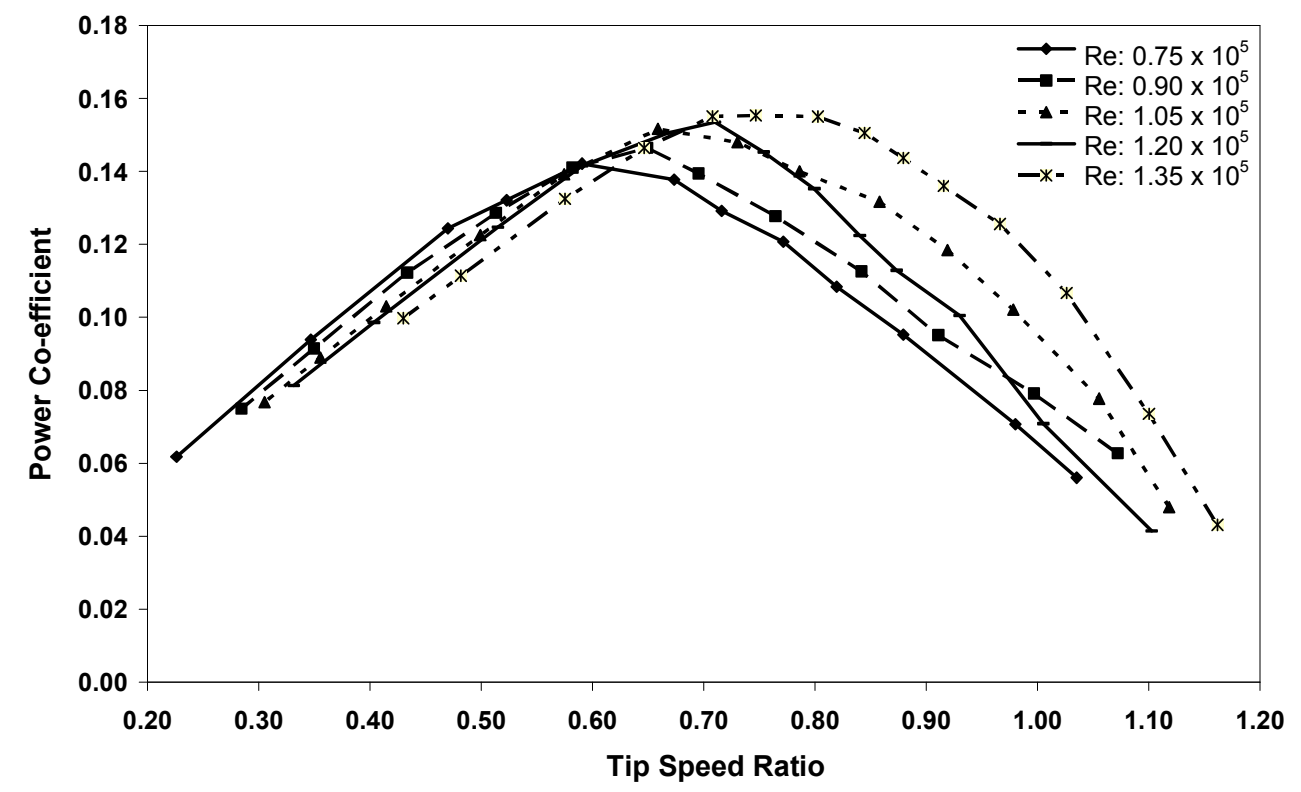

Figure 4. Comparisons of power coefficient vs. tip speed ratio for Five Bladed S-shaped Rotor at different Reynolds number.

Journal of Mechanical Engineering, Vol. ME 44, No. 1, June 2014

Transaction of the Mechanical Engineering Division, The Institution of Engineers, Bangladesh 


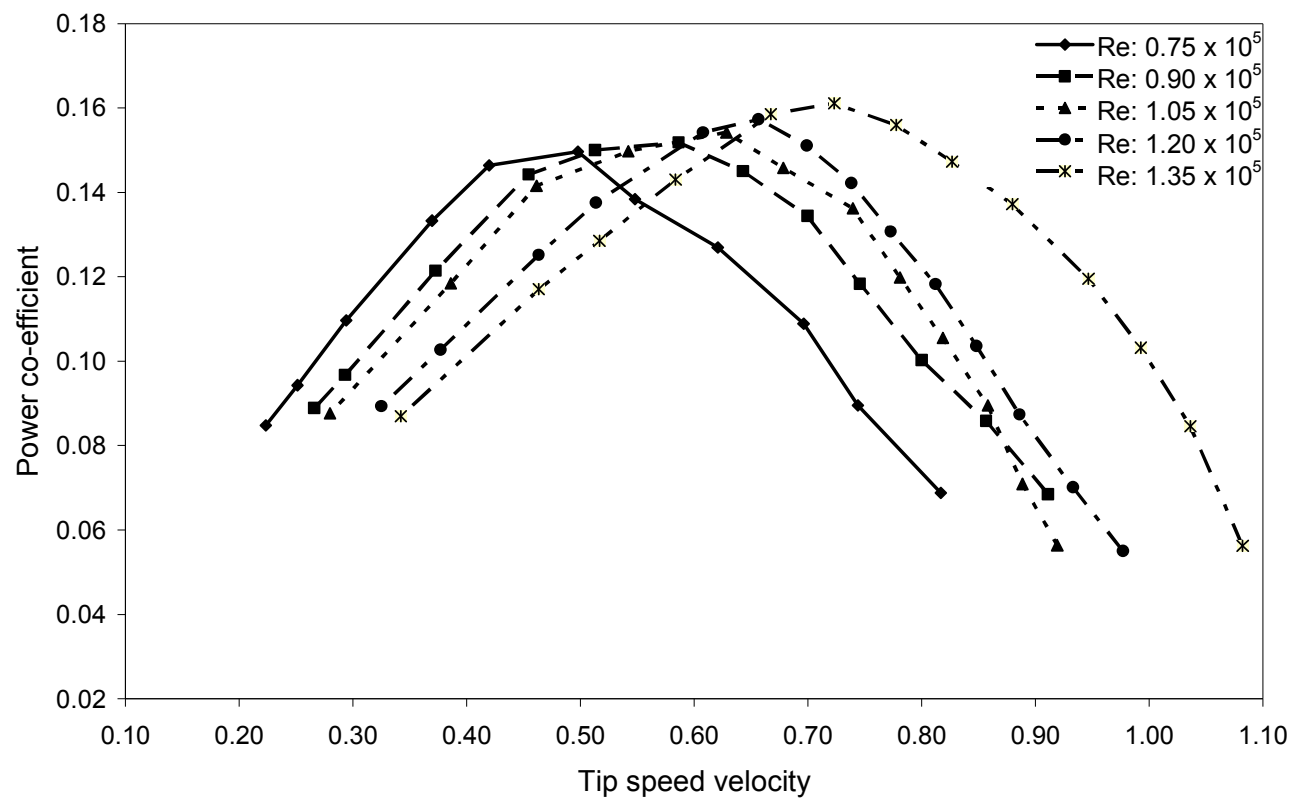

Figure 5. Comparisons of power coefficient vs. tip speed ratio for Six Bladed S-shaped Rotor at different Reynolds number.

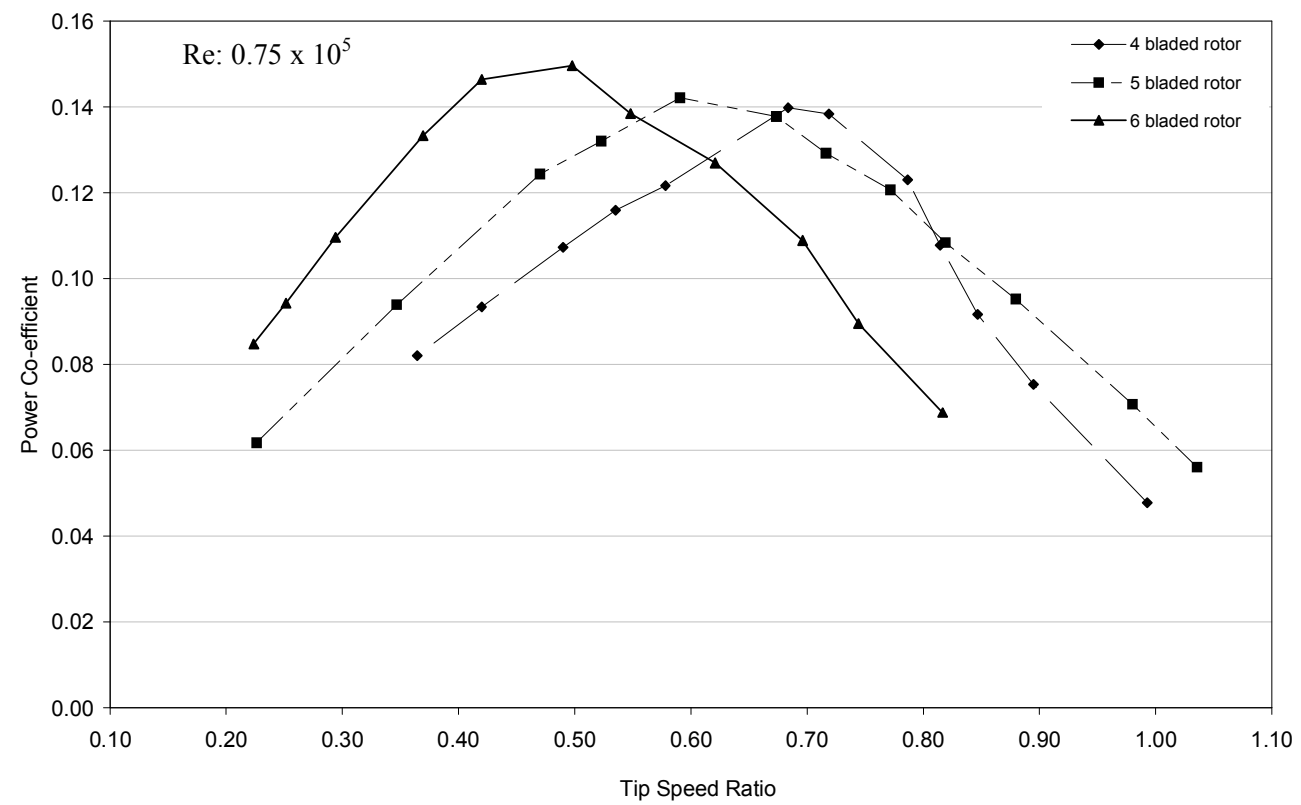

Figure 6. Comparisons of power coefficient versus tip speed ratio of 4, 5 and 6 bladed rotors at Reynolds number of $0.75 \times 10^{5}$.

Journal of Mechanical Engineering, Vol. ME 44, No. 1, June 2014

Transaction of the Mechanical Engineering Division, The Institution of Engineers, Bangladesh 


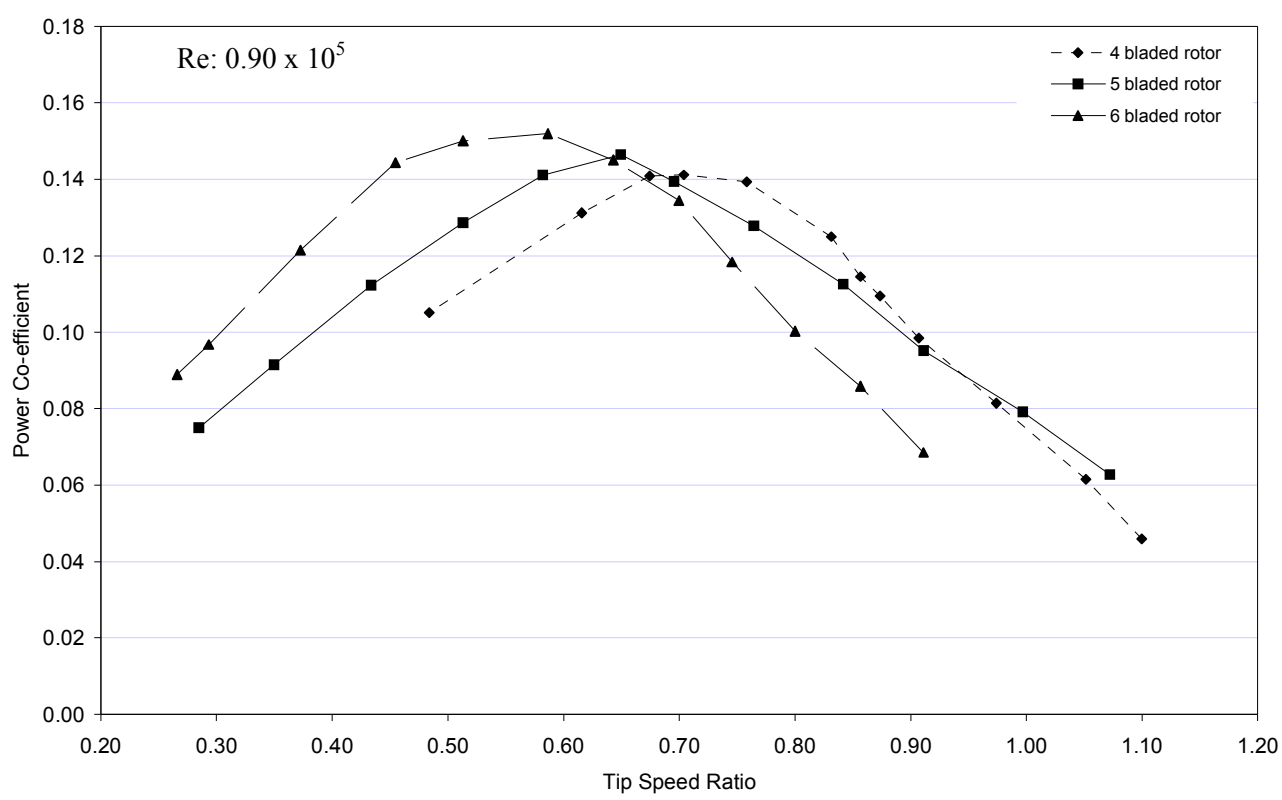

Figure 7. Comparisons of power coefficient versus tip speed ratio of 4, 5 and 6 bladed rotors at Reynolds number of $0.90 \times 10^{5}$.

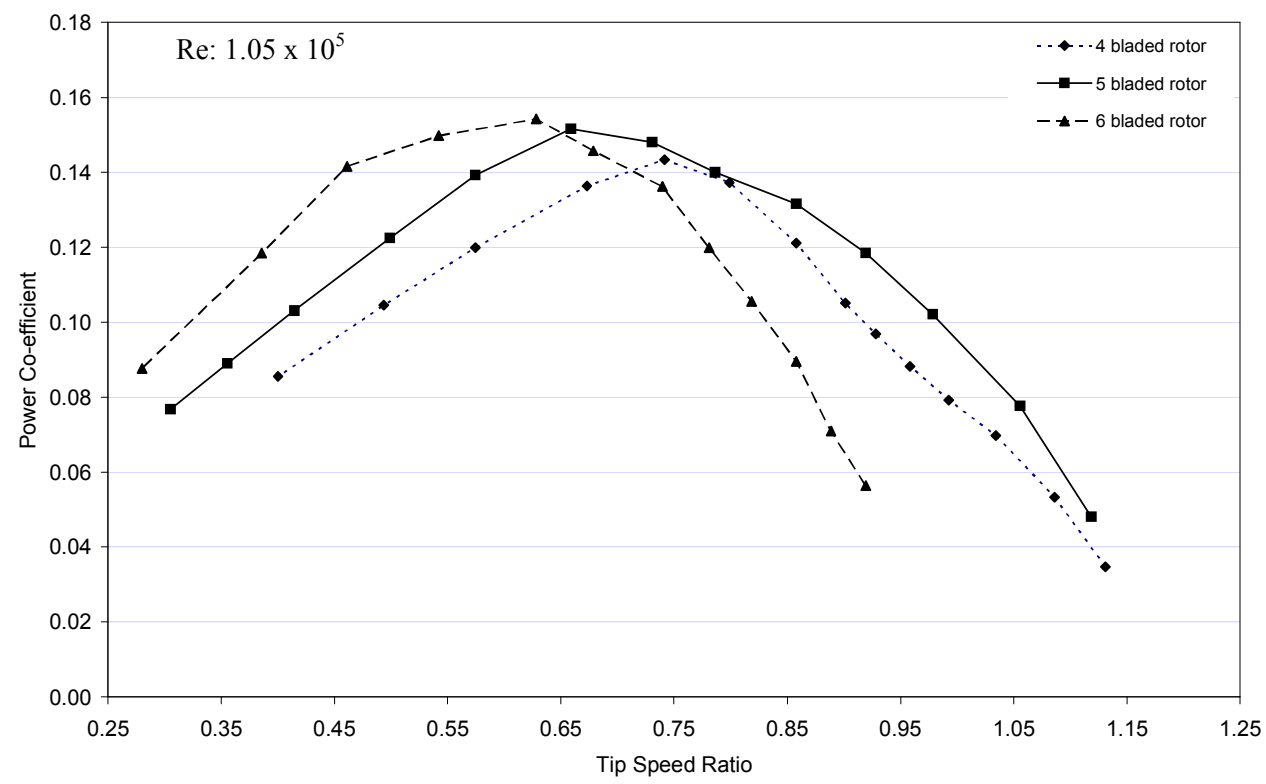

Figure 8. Comparisons of power coefficient versus tip speed ratio of 4, 5 and 6 bladed rotors at Reynolds number of $1.05 \times 10^{5}$.

Journal of Mechanical Engineering, Vol. ME 44, No. 1, June 2014

Transaction of the Mechanical Engineering Division, The Institution of Engineers, Bangladesh 


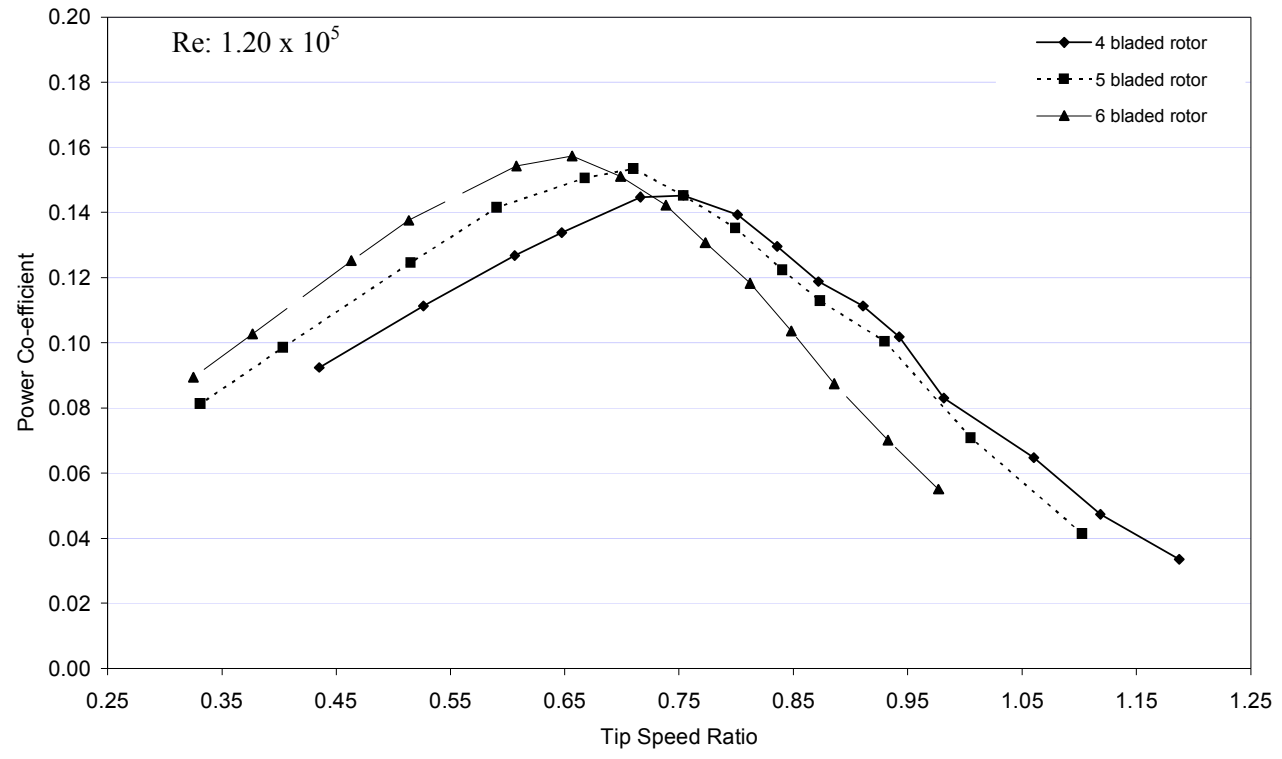

Figure 9. Comparisons of power coefficient versus tip speed ratio of 4, 5 and 6 bladed rotors at Reynolds number of $1.20 \times 10^{5}$.

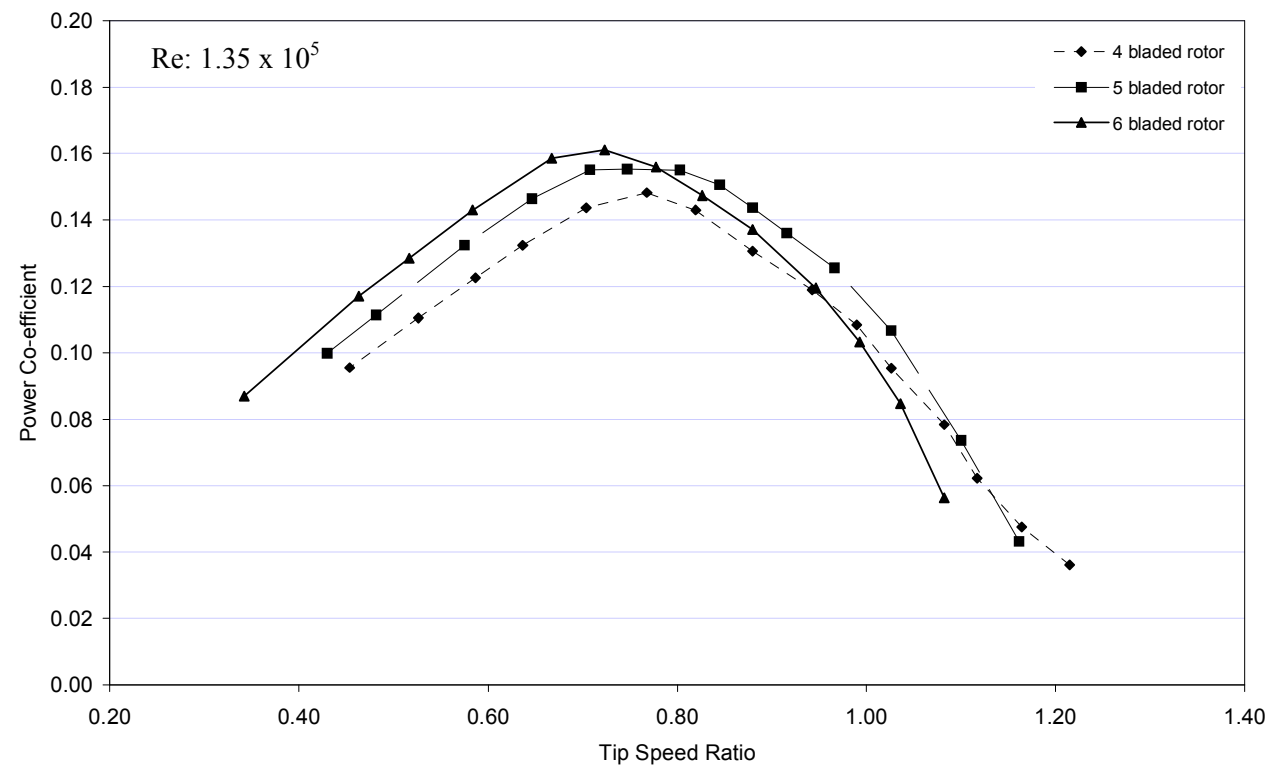

Figure 10. Comparisons of power coefficient versus tip speed ratio of 4, 5 and 6 bladed rotors at Reynolds number of $1.35 \times 10^{5}$. 


\section{CONCLUSION}

From the study, analysis and results of this research work, the following conclusions can be made:

1. For higher value of Reynolds number the value of maximum power coefficient is higher.

2. For the same Reynolds number, the increase in number of blades makes the maximum value of power coefficient higher.

3. By increasing the number of blades of rotor to the optimum limit considering all significant factors and at the same time by increasing its Reynolds number, the power output can be increased to its maximum level.

4. At higher Reynolds number the value of maximum torque co-efficient is slightly lower.

5. At the same Reynolds number for rotor having higher number of blades the maximum value of torque coefficient is also higher.

6. The trend of all curves in each figure (showing comparison among the trend of predicted dynamic aerodynamic characteristics and similar research works) is same.

\section{REFERENCES}

1. Alexander, A.J. and B.P. Holownia, "Wind Tunnel Tests on a Savonius Rotor", J. Industrial Aerodynamics, vol. 3, 1978.

2. Bowden, G.J. and McAleese, S.A., "The Properties of Isolated and Coupled Savonius Rotors", J. of Wind Engineering, vol. 8, no. 4, pp. 271-288, 1984.

3. Huda, M.D., Selim, M.A., Islam, A.K.M.S. and Islam, M.Q., "The Perfomance of an S-Shaped
Savonius Rotor with a Deflecting Plate" RERIC International Energy Journal: Vol. 14, No. 1, pp. 2532, June 1992.

4. Islam, A.K.M.S., Islam, M.Q., Mandal, A.C. and Razzaque, M.M. "Aerodynamic Characteristics of a Stationary Savonius Rotor", RERIC Int. Energy Journal, Vol. 15, No. 2, pp. 125-135, 1993.

5. Islam, A.K.M.S., Islam, M.Q., Razzaque, M.M. and Ashraf, R., "Static Torque and Drag Characteristics of an S-Shaped Savonius Rotor and Prediction of Dynamic Characteristics", Wind Engineering, Vol. 19, No. 6, U.K., 1995.

6. Saha, U.K. and Maity, D., "Optimum Design Configuration of Savonius Rotor through Wind Tunnel Experiments", J. of Wind Engineering and Industrial Aerodynamics, Vol.96, Issues 8-9, pp. 1359-1375, August-September 2008.

7. Kamal, F.M. and Islam, M.Q., "Aerodynamic Characteristics of a Stationary Five Bladed Vertical Axis Vane Type Wind Turbine" J. of Mechanical Engineering, Vol. ME39, No. 2, IEB, December 2008. 8. Swamy, N.V.C. and Fritzsche, A.A., "Aerodynamic Studies on Vertical Axis Wind Turbine", Int. Symposium on Wind Energy Systems, Cambridge, England, September 7-9, 1976.

9. Rahman, M., "Aerodynamic Characteristics of a Three Bladed Savonius Rotor", M.Sc. Engg. Thesis, Dept of Mechanical Engg., BUET, 2000.

10. Bhuiyan, H. K, "Aerodynamic Characteristics of a Four Bladed Savonius Rotor", M.Sc. Engg. Thesis, Dept of Mech. Engg., BUET, 2003.

11. Littler, R.D., "Further Theoretical and Experimental Investigation of the Savonius Rotor", B.E. Thesis, University of Queensland, 1975. 